\title{
Hypocholesterolaemic effects of plant sterol analogues are independent of ABCG5 and ABCG8 transporter expressions in hamsters
}

\author{
Xiaoming Jia ${ }^{1,2}$, Naoyuki Ebine ${ }^{1}$, Isabelle Demonty ${ }^{1}$, Yanwen Wang ${ }^{1,2}$, Robin Beech ${ }^{3}$, Victoria Muise ${ }^{4}$, \\ Marc G. Fortin ${ }^{4}$ and Peter J. H. Jones ${ }^{1,5 *}$ \\ ${ }^{1}$ School of Dietetics and Human Nutrition, McGill University, Macdonald Campus, 21, 111 Lakeshore, Ste-Anne-de-Bellevue, \\ QC, Canada H9X 3V9, Canada \\ ${ }^{2}$ Institute for Nutrisciences and Health, National Research Council of Canada, Charlottetown, PEI C1A 5T1, Canada \\ Departments of ${ }^{3}$ Parasitology and ${ }^{4}$ Plant Science, McGill University, Macdonald Campus, 21, 111 Lakeshore, Ste-Anne-de- \\ Bellevue, QC, Canada H9X 3V9, Canada \\ ${ }^{5}$ Richardson Centre for Functional Foods and Nutraceuticals, Departments of Food Science and Human Nutritional Sciences, 196 \\ Innovation Drive, University of Manitoba Winnipeg, Manitoba, R3T 6C5, Canada
}

(Received 22 October 2006 - Revised 12 February 2007 - Accepted 14 February 2007)

\begin{abstract}
The hypolipidaemic effects of plant sterols are well established. However, mechanisms by which plant sterols lower plasma cholesterol levels, particularly at the molecular level, have not been clearly elucidated. The objective of the present study was to determine whether different plant sterol analogues reduce plasma cholesterol levels by up regulating the sterol transporters ABCG5 and ABCG8 in the liver and/or small intestine. Male Golden Syrian hamsters were divided into eight groups. Groups 1 and 2 were fed a maize starch-casein-sucrose-based diet that did not contain cholesterol (control; Con) or the Con diet with the addition of $0.25 \%$ cholesterol (Ch-Con). Groups 3-8 were fed the Ch-Con diet supplemented with $1 \%$ plant sterols, $1 \%$ plant stanols, $1 \%$ of a plant sterol and stanol mixture (50:50), $1.76 \%$ plant sterol-fish oil esters, or 0.71 or $1.43 \%$ stanol-ascorbic acid esters, respectively. After 5 weeks, the Ch-Con diet up regulated the ABCG5 mRNA expression and tended $(P=0.083)$ to increase ABCG8 mRNA expression in the liver, but did not affect both genes' expression in the small intestine compared with the Con diet. Hamsters fed $0.7 \%$ stanol esters showed lower plasma cholesterol levels $(P<0.001)$ and also lower liver ABCG5 mRNA expression $(P<0.05)$ compared with the Ch-Con diet. Plant stanols, stanol esters, and sterol esters did not affect the ABCG5 or ABCG8 mRNA expressions in the liver and intestine although they reduced plasma cholesterol levels. These results suggest that plant sterols and their derivatives reduce plasma cholesterol levels independently from the mRNA expression of ABCG5 and ABCG8 transporters.
\end{abstract}

Cholesterol: Plant sterols: ABCG5: ABCG8: Hamsters

It has been well documented that dietary supplementation with plant sterols and stanols reduces plasma cholesterol levels in human subjects and animals ${ }^{1-9}$. Plant sterols and stanols are not water soluble and possess low solubility in fats. It is believed that solubility characteristics affect the bioavailability and cholesterol-lowering efficacy of sterols and stanols. Thus, a large body of research has been conducted attempting to modify the structure of plant sterols and stanols, and the esterification to fatty acids ${ }^{10,11}$ or ascorbic acid has been extensively studied in the past years ${ }^{12-14}$. Accordingly, several different analogues of plant sterols and stanols are currently available as functional food ingredients or nutraceuticals.

The interference with cholesterol incorporation into micelles has long been thought to be the possible mechanism by which plant sterols and stanols inhibit cholesterol absorption ${ }^{15,16}$. However, this mechanism cannot explain the observation that plasma cholesterol levels were significantly decreased in hamsters after plant sterols were injected intraperitoneally ${ }^{17}$. Recent advances in molecular research have indicated that the sterol transporter-mediated cholesterol efflux in the enterocytes and cholesterol secretion in the liver may play important roles in cholesterol absorption and metabolism ${ }^{18-22}$. It has been found that in sitosterolaemic subjects, cholesterol transporters ABCG5 and ABCG8 are mutated, resulting in sterol secretion disorders in the liver and enterocytes ${ }^{18-20}$. The role of ABCG5 and ABCG8 transporters in cholesterol efflux has further been demonstrated in transgenic mice by expressing both human and mouse ABCG5 and ABCG8 genes. Results showed approximately $50 \%$ reductions in cholesterol absorption and marked increases in biliary cholesterol secretion and faecal neutral sterol excretion compared with their wild-type littermates ${ }^{22}$. In contrast, the ABCG5-/- and ABCG8-/- mice presented increased absorption of dietary sterols and impaired biliary

\footnotetext{
Abbreviations: Ch-Con, control diet with $0.25 \%$ cholesterol; Con, control diet; Sta, Ch-Con diet with $1 \%$ plant stanols; Ste, Ch-Con diet with $1 \%$ plant sterols; SteF, sterols esterified to fish oil; StaA, stanols esterified to ascorbic acid.

* Corresponding author: Dr Peter J. H. Jones, fax +1 204474 7552, email peter_jones@umanitoba.ca
} 
sterol excretion and had plasma sitosterol levels 30-fold higher than their wild-type littermates ${ }^{21}$.

Taken together, these data suggest that ABCG5 and ABCG8 transporters regulate cholesterol efflux out of the enterocytes and cholesterol secretion in the liver. The few studies conducted to date have failed to demonstrated any action of plant sterols or stanols on expression of ABCG5 and ABCG8 in the intestine ${ }^{23-25}$. The effect of plant sterols or stanols on the expression of these two genes in the liver has rarely been studied. It still remains unclear about the molecular mechanisms of action of different plant sterol analogues on cholesterol metabolism. Therefore, the present study was undertaken to determine whether the cholesterollowering effects of different plant sterol analogues are due to ABCG5- and ABCG8-mediated alterations in cholesterol secretion from the liver and cholesterol efflux from the enterocytes in hamsters. Because hamster lipid composition and biochemistry more closely resemble those of man than those of other rodents, the hamster has been considered as a good model for studying human cholesterol metabolism ${ }^{26,27}$.

\section{Materials and methods}

\section{Animals and diets}

Eighty male Golden Syrian hamsters (Charles River Laboratories, Montreal, QC, Canada), weight 100-120 g, were housed individually in stainless-steel mesh cages with a $12 \mathrm{~h}$ light-dark cycle. Animals were fed regular rodent chow with free access to water. After 2 weeks of adaptation, hamsters were randomly divided into eight groups and fed experimental diets for 5 weeks. Group 1 was given a semi-purified maize starch-casein-sucrose diet with no cholesterol added (control; Con). Group 2 was given the Con diet with the addition of $0.25 \%$ cholesterol (Ch-Con). Groups 3 to 8 were given the $\mathrm{Ch}-\mathrm{Con}$ diet with either $1 \%$ plant sterols (Ste),
$1 \%$ plant stanols (Sta), $1 \%$ Ste and Sta mixture (50:50), $1.76 \%$ sterols esterified to fish oil (SteF), or 0.71 or $1.43 \%$ stanols esterified to ascorbic acid $(0.7 \%$ StaA or $1.4 \%$ $\mathrm{StaA}$ ), respectively. All diets contained $5 \%$ fat provided in the form of a mixture of beef tallow and safflower-seed oil to yield a PUFA:SFA ratio of $0 \cdot 4$. Composition of the diets is shown in Table 1. Diet SteF had an equivalent amount of plant sterols as the Ste diet. Diets $0.7 \%$ StaA and $1.4 \%$ StaA provided an equivalence of $0.5 \%$ and $1 \%$ free plant stanols, respectively. Plant sterol analogues were mixed into the oil at $55^{\circ} \mathrm{C}$ before blending into diets. Diets were prepared every 2 weeks and stored at $-20^{\circ} \mathrm{C}$.

After 5 weeks on the experimental diets, hamsters were anaesthetized with halothane and killed by decapitation. Blood was collected into tubes containing EDTA and placed on ice. Plasma was separated by centrifugation and stored at $-80^{\circ} \mathrm{C}$ until analysis. Liver and proximal small intestine were quickly removed, frozen in liquid $\mathrm{N}_{2}$, and stored at $-80^{\circ} \mathrm{C}$ for mRNA measurement. The experiment was reviewed and approved by the Animal Care and Research Ethics Committee of McGill University and was conducted in accordance with the guidelines of the Canadian Council on Animal Care.

\section{Plasma lipid analysis}

Plasma total cholesterol, HDL-cholesterol concentrations were measured in duplicate by enzymic methods (Roche Diagnostics, Laval, QC, Canada). HDL-cholesterol was measured after precipitation of apoB containing lipoproteins with dextran sulfate and magnesium chloride ${ }^{28}$. Because the Friedewald equation $^{29}$ may not be applicable in hamsters, non-HDL-cholesterol (VLDL- + intermediate-density lipoprotein- + LDL-cholesterol) instead of LDL-cholesterol was used and calculated by subtracting HDL-cholesterol from total cholesterol.

Table 1. Composition of the experimental diets $(\%, w / w)^{*}$

\begin{tabular}{|c|c|c|c|c|c|c|c|c|}
\hline Diet... & Con & Ch-Con & Ste & Mix & Sta & SteF & $0.7 \%$ StaA & $1.4 \%$ StaA \\
\hline Casein & $20 \cdot 0$ & $20 \cdot 0$ & $19 \cdot 8$ & $19 \cdot 8$ & $19 \cdot 8$ & $19 \cdot 6$ & $19 \cdot 8$ & $19 \cdot 7$ \\
\hline Maize starch & $28 \cdot 0$ & $28 \cdot 0$ & $27 \cdot 7$ & $27 \cdot 7$ & $27 \cdot 7$ & $27 \cdot 5$ & $27 \cdot 7$ & $27 \cdot 6$ \\
\hline Sucrose & $36 \cdot 3$ & $36 \cdot 0$ & $35 \cdot 6$ & $35 \cdot 6$ & $35 \cdot 6$ & $35 \cdot 3$ & $35 \cdot 6$ & 35.5 \\
\hline Beef tallow and safflower-seed oilt & $5 \cdot 0$ & $5 \cdot 0$ & $5 \cdot 0$ & $5 \cdot 0$ & $5 \cdot 0$ & $5 \cdot 0$ & $5 \cdot 0$ & $5 \cdot 0$ \\
\hline Cellulose & $5 \cdot 0$ & $5 \cdot 0$ & 4.9 & 4.9 & 4.9 & 4.9 & 4.9 & 4.9 \\
\hline DL-Methionine & 0.5 & 0.5 & 0.5 & 0.5 & 0.5 & 0.5 & 0.5 & 0.5 \\
\hline Mineral mixture & 4 & 4 & 4 & 4 & 4 & 4 & 4 & 4 \\
\hline Vitamin mixture & 1 & 1 & 1 & 1 & 1 & 1 & 1 & 1 \\
\hline Choline bitartrate & 0.2 & 0.2 & 0.2 & 0.2 & 0.2 & 0.2 & 0.2 & 0.2 \\
\hline Butylated hydroxytoluene & 0.02 & 0.02 & 0.02 & 0.02 & 0.02 & 0.02 & 0.02 & 0.02 \\
\hline Cholesterol & - & 0.25 & 0.25 & 0.25 & 0.25 & 0.25 & 0.25 & 0.25 \\
\hline Plant sterolsł & - & - & 1.0 & - & - & - & - & - \\
\hline Mixture (Ste and Sta) $\ddagger$ & & & & 1.0 & & & & \\
\hline Plant stanolsł & - & - & - & & 1.0 & - & - & - \\
\hline SteF $\ddagger$ & - & - & - & - & - & $1.76^{*}$ & - & - \\
\hline StaAł & - & - & - & - & - & - & $0.71^{*}$ & $1.43^{*}$ \\
\hline
\end{tabular}

Con, control diet without cholesterol; Ch-Con, control diet with addition of $0.25 \%$ cholesterol; Ste, Ch-Con diet with $1 \%$ plant sterols; Mix, Ch-Con diet with $0.5 \%$ plant sterols and $0.5 \%$ plant stanols; Sta, Ch-Con diet with $1 \%$ plant stanols; SteF, Ch-Con diet with $1.76 \%$ plant sterols esterified to fish oil; $0.7 \%$ StaA, Ch-Con diet with $0.7 \%$ plant stanols esterified to ascorbic acid, $1.4 \%$ StaA, Ch-Con diet with $1.4 \%$ plant stanols esterified to ascorbic acid. *All diet ingredients except safflower-seed oil were purchased from ICN Biomedicals (Aurora, OH, USA) and diets were prepared in house. † Safflower-seed oil was purchased from a local supermarket in Montreal, QC, Canada.

$\ddagger$ Plant sterols and their different analogues were provided by Forbes Medi-Tech Inc.,Vancouver, BC, Canada. 


\section{Hamster ABCG5 and ABCG8 sequences}

Because there was no genomic DNA or cDNA sequence available for hamster ABCG5 and ABCG8, we obtained a part of cDNA sequence of both genes using degenerated primers that were designed based on rat, mouse and human cDNA sequences. Briefly, after alignment of rat, mouse and human cDNA sequences for each gene, the most conservative sequence regions were identified by the MacVector software. Then the degenerated primers were designed within the conservative regions using the Oligo software. The target cDNA templates from one hamster were amplified with the degenerated primers by PCR (Perkin Elmer Applied Biosystems, Wellesley, USA). After separation from the templates by electrophoresis on acrylamide gel, the PCR products were purified and cloned using plasmid $\mathrm{pCR}_{4}{ }^{-}$ TOPO (Invitrogen, Ontario, Canada). Recombinant plasmids were purified using a plasmid mini kit (Qiagen, Ontario, Canada). The target cDNA was amplified by PCR and sequenced by the Genome Quebec Innovation Centre at McGill University (Montreal, Canada). The cDNA sequences of hamster ABCG5 and ABCG8 showed over $80 \%$ homology compared with the corresponding regions of the rat and mouse sequences and were used to design primers to measure ABCG5 and ABCG8 mRNA expression by quantitative real-time PCR.

\section{Measurement of messenger ribonucleic acid expression of $A B C G 5$ and $A B C G 8$}

Total RNA was extracted and purified from the liver and proximal small intestine using the RNeasy Mini Kit (Qiagen, Mississauga, ON, Canada). A sample $(2 \mu \mathrm{g})$ of RNA was transcribed to cDNA using the Ominiscript RT kit (Qiagen). Real-time PCR was performed on a LightCycler (Roche, Switzerland) using the QuantiTect SYBR Green PCR kit (Qiagen). Primer sequences were $5^{\prime}$-GGA AGG GGA GGT GTT TGT-3' and $5^{\prime}$-GCC AGC ATC GCC GTG TAG-3' for ABCG5, 5'CAT CAT TGG CTT CCT TTA- $3^{\prime}$ and CCG CTC CGA GTG ACA TTT- $3^{\prime}$ for ABCG8, and $5^{\prime}$-AGT ATT CCC CAT CGT-3' and 5'-TCA TCC CAG TTC GTC ACA-3' for $\beta$-actin. The real-time PCR reaction solution consisted of $10 \mu \mathrm{l}$ QuantiTect SYBR Green PCR mixture containing $2.5 \mathrm{mM}-\mathrm{MgCl}_{2}, 1 \mu \mathrm{l}$ forward primer $(0.5 \mu \mathrm{M}), 1 \mu \mathrm{l}$ reverse primer $(0.5 \mu \mathrm{M})$, and $6 \mu \mathrm{l}$ RNase-free water. LightCycler glass capillaries were filled with $18 \mu$ l of the real-time PCR reaction solution and $2 \mu \mathrm{l}$ cDNA templates. The capillaries were closed, centrifuged and placed into the LightCycler rotor. The real-time PCR was optimized to have initial activation at $95^{\circ} \mathrm{C}$ for $15 \mathrm{~min}$, denaturation at $94^{\circ} \mathrm{C}$ for $15 \mathrm{~s}$, annealing at $55^{\circ} \mathrm{C}$ for $20 \mathrm{~s}$, and extension at $72^{\circ} \mathrm{C}$ for $15 \mathrm{~s}$ with a single fluorescence measurement and up to forty cycles. The specificity of primers was validated by acrylamide gel electrophoresis and real-time PCR to ascertain there were no significant non-specific products and primer dimmers formed before the sample analysis. Data were normalized against an endogenous reference gene, $\beta$-actin. Purified plasmid, diluted to certain concentration, was used as an external calibrator across all the measurements.

\section{Data analysis and statistics}

Data from plasma lipids as well as the liver and intestine ABCG5 and ABCG8 mRNA were analysed by one-way
ANOVA. The gene expression data were logarithmically transformed before analysis. When a significant ANOVA result was obtained, the least-squares means test was used to test differences between treatments. Relationships between plasma total cholesterol concentrations and ABCG5 or ABCG8 mRNA levels were analysed using Pearson's correlation coefficients. All statistical analyses were conducted using the general linear model procedure of SAS software (SAS Institute Inc., Cary, NC, USA). Significance level was set at $P<0 \cdot 05$. Data are presented as mean values with their standard errors.

\section{Results}

\section{Body weight and food consumption}

The dietary supplementation of cholesterol and different phytosterol analogues did not affect body weights of hamsters as compared with the Con diet. Similarly, there were no changes in the average or total food intakes during the last 2 weeks.

\section{Lipid profiles}

The effects of experimental diets on hamster plasma lipid profiles are shown in Table 2 . The inclusion of $0.25 \%$ cholesterol in the diet increased $(P<0.0001)$ plasma total cholesterol level by $58.4 \%$ as compared with the Con diet. When animals were supplemented with 0.7 or $1.4 \%$ stanol-ascorbic acid esters, their plasma total cholesterol levels were reduced $(P<0.0001)$ by 34.0 and $45.7 \%$, respectively, compared with those fed the Ch-Con diet. The addition of stanols or sterol-fish oil esters to the $\mathrm{Ch}$-Con diet lowered $(P<0.05)$ total cholesterol levels by 13.7 and $19.7 \%$, respectively. Sterols and the mixture of sterols and stanols did not have a significant effect on plasma total cholesterol levels. Plasma non-HDL-cholesterol concentrations were 16.6, $39 \cdot 2$ and $54.2 \%$ lower $(P<0.05)$ in hamsters supplemented with sterol-fish oil esters, 0.7 and $1.4 \%$ stanol-ascorbic acid

Table 2. Effects of phytosterol analogues on lipid profiles in hamsters* (Mean values with their standard errors)

\begin{tabular}{|c|c|c|c|c|c|c|}
\hline \multirow[b]{2}{*}{ Diet } & \multicolumn{2}{|c|}{$\begin{array}{l}\text { Total choles- } \\
\text { terol (mmol/l) }\end{array}$} & \multicolumn{2}{|c|}{$\begin{array}{l}\text { Non-HDL- } \\
\text { cholesterol } \\
(\mathrm{mmol} / \mathrm{l}) \dagger\end{array}$} & \multicolumn{2}{|c|}{$\begin{array}{l}\text { HDL-cholesterol } \\
(\mathrm{mmol} / \mathrm{l})\end{array}$} \\
\hline & Mean & SEM & Mean & SEM & Mean & SEM \\
\hline Con & $4 \cdot 01^{d}$ & 0.11 & $2 \cdot 18^{c}$ & 0.10 & $1 \cdot 83^{c, d}$ & 0.12 \\
\hline Ch-Con & $6 \cdot 35^{a}$ & 0.27 & $3 \cdot 67^{a, b}$ & 0.33 & $2 \cdot 68^{a}$ & 0.15 \\
\hline Ste & $6 \cdot 68^{a}$ & 0.26 & $4 \cdot 30^{\mathrm{a}}$ & 0.24 & $2 \cdot 38^{a, b}$ & 0.09 \\
\hline Mix & $5.96^{a, b}$ & 0.47 & $3 \cdot 84^{a, b}$ & 0.22 & $2 \cdot 12^{\mathrm{b}, \mathrm{c}, \mathrm{d}}$ & 0.15 \\
\hline Sta & $5 \cdot 48^{\mathrm{b}, \mathrm{c}}$ & 0.26 & $3 \cdot 32^{a, b}$ & 0.25 & $2 \cdot 16^{\mathrm{b}, \mathrm{c}}$ & 0.15 \\
\hline SteF & $5 \cdot 10^{c}$ & 0.17 & $3.06^{c}$ & 0.12 & $2 \cdot 04^{\mathrm{b}, \mathrm{c}, \mathrm{d}}$ & 0.09 \\
\hline $0.7 \%$ StaA & $4 \cdot 19^{d}$ & 0.28 & $2 \cdot 23^{c}$ & 0.22 & $1.96^{c, d}$ & 0.13 \\
\hline $1.4 \%$ StaA & $3.45^{\mathrm{d}}$ & 0.12 & $1.68^{\mathrm{C}}$ & 0.06 & $1 \cdot 77^{\mathrm{d}}$ & 0.11 \\
\hline
\end{tabular}

Con, control diet without cholesterol; Ch-Con, control diet with addition of $0.25 \%$ cholesterol; Ste, Ch-Con diet with $1 \%$ plant sterols; Mix, Ch-Con diet with $0.5 \%$ plant sterols and $0.5 \%$ plant stanols; Sta, Ch-Con diet with $1 \%$ plant stanols; SteF, Ch-Con diet with $1.76 \%$ plant sterols esterified to fish oil; $0.7 \%$ StaA Ch-Con diet with $0.7 \%$ plant stanols esterified to ascorbic acid, $1.4 \%$ StaA, Ch-Con diet with $1.4 \%$ plant stanols esterified to ascorbic acid.

a,b,c,d Mean values within a column with unlike superscript letters are significantly different $(P<0.05$; pairwise comparisons among the eight groups for each lipid parameter).

* For composition of the experimental diets, see Table 1.

† VLDL- + intermediate-density lipoprotein- + LDL-cholesterol. 
esters while not affected by sterols, stanols, and the sterolstanol mixture, respectively, relative to hamsters fed the Ch-Con diet. Plasma HDL-cholesterol levels were lower $(P<0.05)$ in hamsters supplemented with sterol-stanol mixture, stanols, sterol-fish oil esters, and the two doses of stanolascorbic acid esters relative to animals given the $\mathrm{Ch}-\mathrm{Con}$ diet.

\section{Gene expression of $A B C G 5$ and $A B C G 8$}

The inclusion of cholesterol in the diet increased $(P<0.05)$ plasma cholesterol levels. The $\mathrm{Ch}-\mathrm{Con}$ diet also increased the ABCG5 mRNA and tended $(P=0.083)$ to increase ABCG8 mRNA expression in the liver compared with the Con diet (Fig. 1). Plasma total cholesterol levels were positively correlated with liver ABCG5 $(r$ 0.36; $P=0.0018)$ and ABCG8 ( $r$ 0.29; $P=0.011)$ mRNA levels. The addition of $0.7 \%$ stanol-ascorbic acid esters to the Ch-Con diet reduced $(P<0.05)$ plasma cholesterol levels and also the expression of ABCG5 levels as compared with the Ch-Con diet. The other sterol analogues appeared to lower the expression of ABCG5 and ABCG8 mRNA in the liver, but these reductions were not significant as compared with the Ch-Con diet (Fig. 1). No differences were observed in both ABCG5 and ABCG8 mRNA levels in the proximal small intestine among all the treatments (Fig. 2).

\section{Discussion}

The present study demonstrated that different phytosterol analogues possess various cholesterol-lowering efficacies, with the stanol-ascorbic acid esters showing the strongest effect, followed by sterol-fish oil esters and stanols. The supplementation of plant sterols and the mixture of sterols and stanols did not result in significant changes in plasma cholesterol levels. Plant sterols and their analogues did not up regulate the expression of ABCG5 and ABCG8. In contrast, they reduced or tended to reduce the expression of both genes in the liver. The expression of ABCG5 and ABCG8 in the intestine was not affected by plant sterols and their different analogues. The addition of cholesterol in the diet significantly up regulated ABCG5 mRNA expression and showed a tendency of increasing the expression of ABCG8 in the liver, while showing no effect on either gene in the small intestine.

Accumulating evidence has demonstrated that plant sterols inhibit cholesterol absorption, and thus lower plasma cholesterol levels ${ }^{5,30}$. The interference with cholesterol incorporation into micelles in the intestinal lumen is the most widely accepted mechanism by which plant sterols reduce plasma cholesterol levels ${ }^{15,16}$. Recent advances in molecular research have revealed that the sterol transporters ABCG5 and ABCG8 are critical to cholesterol efflux in the enterocytes and consequently cholesterol absorption. It has been speculated that plant sterols may inhibit cholesterol absorption, at least in part, through up regulating the expression of ABCG5 and ABCG8 in enterocytes. However, data from the present study do not support this hypothesis. Plant sterols and stanols and their esterified forms had no effect on either ABCG5 or ABCG8 mRNA levels in the small intestine, which is in agreement with previous studies in hamsters supplemented with stanol esters ${ }^{23}$ or in mice given plant sterols or stanols ${ }^{24,25}$. The present results demonstrated that different phytosterol analogues possess various cholesterol-lowering efficacies which are independent from the expression of sterol transporters ABCG5 and ABCG8 in the intestine.

In addition to cholesterol absorption in the intestine, the liver plays a central role in cholesterol homeostasis. Cholesterol secretion is one of the mechanisms by which the liver excretes cholesterol. Because the sterol transporters ABCG5 and ABCG8 mediate cholesterol secretion into bile $21,22,31$, plant sterols have been thought to up regulate the expression of these two genes in the liver and thus cholesterol excretion, thereby lowering plasma cholesterol concentrations. Paradoxically, the present study showed that stanol esters $(0.7 \%$ in the diet) decreased liver ABCG5 mRNA levels and appeared to lower ABCG8 mRNA expression. The insignificant effect of the other phytosterol analogues on ABCG5 and ABCG8
(A)

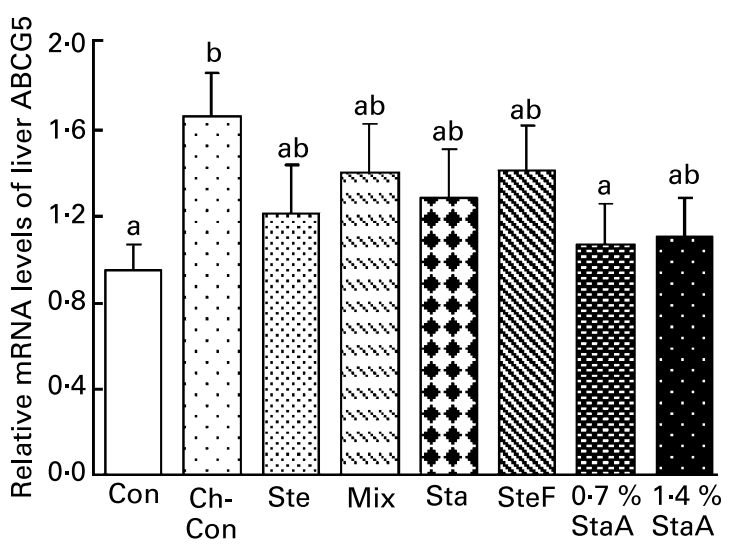

(B)

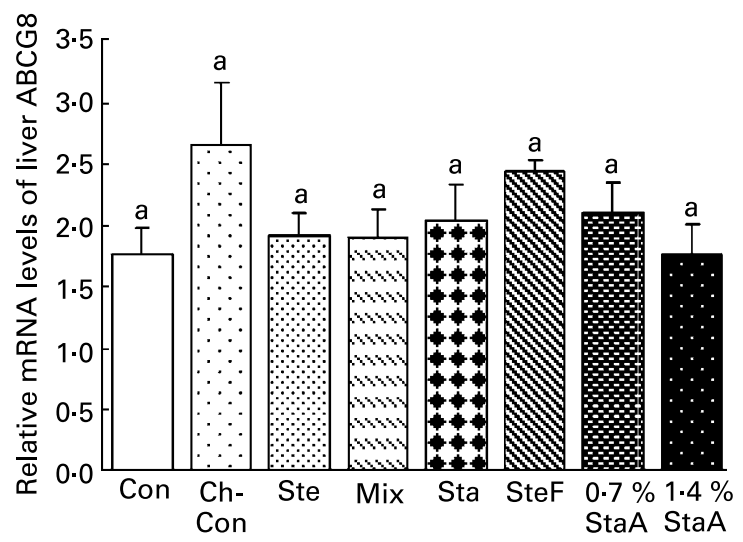

Fig. 1. Effects of cholesterol and different phytosterol analogues on sterol transporters ABCG5 (A) and ABCG8 (B) mRNA expressions in the liver. Con, control diet without cholesterol; Ch-Con, control diet with addition of $0.25 \%$ cholesterol; Ste, Ch-Con diet with $1 \%$ plant sterols; Mix, Ch-Con diet with $0.5 \%$ plant sterols and $0.5 \%$ plant stanols; Sta, Ch-Con diet with $1 \%$ plant stanols; SteF, Ch-Con diet with $1.76 \%$ plant sterols esterified to fish oil, $0.7 \%$ StaA, Ch-Con diet with $0.7 \%$ plant stanols esterified to ascorbic acid, $1.4 \%$ StaA, Ch-Con diet with $1.4 \%$ plant stanols esterified to ascorbic acid. Values are means ( $n$ 10), with their standard errors represented by vertical bars. Values were normalized against endogenous internal reference $\beta$-actin and an external calibrator for every run. Data were logarithmically transformed before the statistical analysis. ${ }^{a, b}$ Mean values with unlike letters were significantly different $(P<0 \cdot 05)$. 
(A)

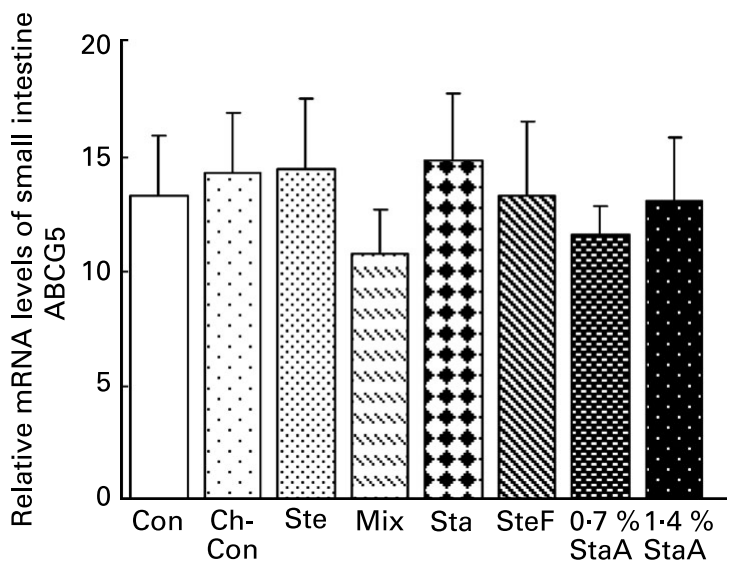

(B)

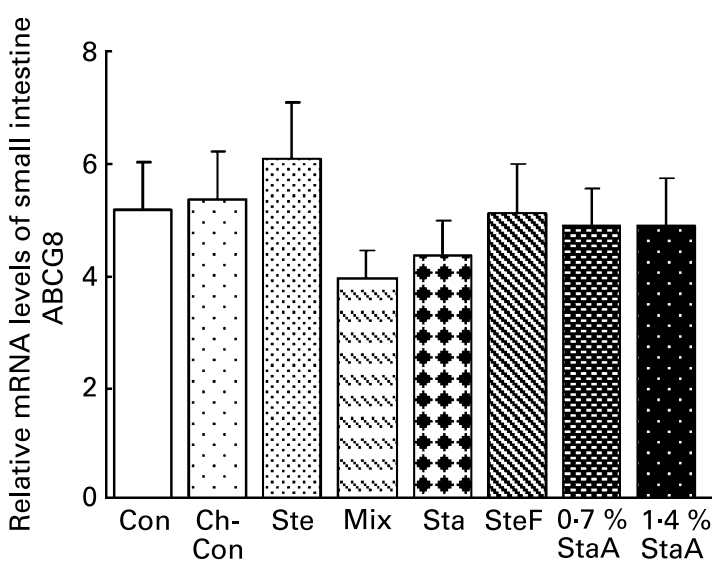

Fig. 2. Effects of cholesterol and different phytosterol analogues on $A B C G 5(A)$ and $A B C G 8$ (B) mRNA expressions in the proximal small intestine. Con, control diet without cholesterol; Ch-Con, control diet with addition of $0.25 \%$ cholesterol; Ste, Ch-Con diet with $1 \%$ plant sterols; Mix, Ch-Con diet with $0.5 \%$ plant sterols and $0.5 \%$ plant stanols; Sta, Ch-Con diet with $1 \%$ plant stanols; SteF, Ch-Con diet with $1.76 \%$ plant sterols esterified to fish oil, $0.7 \%$ StaA, Ch-Con diet with $0.7 \%$ plant stanols esterified to ascorbic acid, $1.4 \%$ StaA, Ch-Con diet with $1.4 \%$ plant stanols esterified to ascorbic acid. Values are means ( $n 10)$, with their standard errors represented by vertical bars. Values were normalized against endogenous internal reference $\beta$-actin and an external calibrator for every run. Data were logarithmically transformed before the statistical analysis.

mRNA expressions in the liver could be due to the large intragroup variations observed. These data suggest that the cholesterol-lowering effect of phytosterol analogues does not rely on ABCG5 and ABCG8 expressions in the liver.

The expression of ABCG5 in the liver was significantly increased by dietary cholesterol and was positively associated with plasma cholesterol levels. This observation is consistent with previous studies in mice demonstrating that ABCG5 and ABCG8 mRNA expressions in the liver were up regulated by dietary cholesterol levels in a dose-dependent manner ${ }^{18,32,-34}$. The effect of dietary cholesterol on the expression of ABCG5 and ABCG8 in the small intestine is controversial. The present study did not show a significant effect of cholesterol on these two genes in the small intestine in hamsters. Some studies in mice have shown that dietary supplementation of cholesterol increases the expression of ABCG5 and ABCG8 in the small intestine $^{18,32,33,35}$ while others did not show any effect ${ }^{25,36}$. Studies in hamsters ${ }^{23}$ and rats ${ }^{34}$ did not show any effect of dietary cholesterol on ABCG5 and ABCG8 expressions in the small intestine. These discrepancies may be due to differences in cholesterol absorption between different species, as shown in other studies conducted previously ${ }^{18,37}$. For example, mice are resistant to $2 \%$ dietary cholesterol and show little changes in plasma cholesterol levels ${ }^{18}$, while hamsters absorb cholesterol more efficiently and quickly develop hypercholesterolaemia when $0.25 \%$ cholesterol is supplemented in the $\operatorname{diet}^{37}$. The ABCG5 and ABCG8 sterol transporters in the small intestine may be less responsive to dietary cholesterol levels in hamsters than in mice.

In summary, the hypocholesterolaemic effects of different plant sterol analogues are not mediated by increases in the expression of sterol transporters ABCG5 and ABCG8 in the liver or intestine. Plasma cholesterol levels up regulate the expression of ABCG5 and ABCG8 in the liver, but not in the small intestine. To elucidate the molecular mechanism by which plant sterols and their different analogues lower plasma cholesterol levels, the effect of plant sterols and their analogues on the expression of other genes involved in cholesterol absorption and metabolism warrants further investigation.

\section{Acknowledgements}

The authors thank Mrs Guanhua Wang from the Department of Parasitology at McGill University for providing mentoring in laboratory techniques. We are also thankful to Mr Gordon Bingham from the Department of Parasitology at McGill University for his assistance in animal care. The study was supported by a grant from the Natural Sciences and Engineering Research Council of Canada. The sterols and their different analogues were a kind gift from Forbes Medi-Tech Inc. (Vancouver, BC, Canada).

\section{References}

1. Pollak OJ (1953) Reduction of blood cholesterol in man. Circulation 7, 702-706.

2. Grundy SM (1983) Absorption and metabolism of dietary cholesterol. Annu Rev Nutr 3, 71-96.

3. Jones PJ, Ntanios FY, Raeini-Sarjaz M \& Vanstone CA (1999) Cholesterol-lowering efficacy of a sitostanol-containing phytosterol mixture with a prudent diet in hyperlipidemic men. Am J Clin Nutr 69, 1144-1150.

4. Hallikainen MA, Sarkkinen ES, Gylling H, Erkkila AT \& Uusitupa MI (2000) Comparison of the effects of plant sterol ester and plant stanol ester-enriched margarines in lowering serum cholesterol concentrations in hypercholesterolaemic subjects on a low-fat diet. Eur J Clin Nutr 54, 715-725.

5. Vanstone CA, Raeini-Sarjaz M, Parsons WE \& Jones PJ (2002) Unesterified plant sterols and stanols lower LDL-cholesterol concentrations equivalently in hypercholesterolemic persons. Am J Clin Nutr 76, 1272-1278. 
6. Hendriks HF, Brink EJ, Meijer GW, Princen HM \& Ntanios FY (2003) Safety of long-term consumption of plant sterol estersenriched spread. Eur J Clin Nutr 57, 681-692.

7. Homma $\mathrm{Y}$, Ikeda I, Ishikawa $\mathrm{T}$, Tateno $\mathrm{M}$, Sugano $\mathrm{M}$ \& Nakamura H (2003) Decrease in plasma low-density lipoprotein cholesterol, apolipoprotein B, cholesteryl ester transfer protein, and oxidized low-density lipoprotein by plant stanol ester-containing spread: a randomized, placebo-controlled trial. Nutrition 19, 369-374.

8. Skeaff CM, Thoma C, Chisholm A, Mann J \& Williams S (2004) Effects on plasma lipids when plant sterol enriched fat spread or carbohydrate provide replacement energy for saturated fatty acids. Asia Pac J Clin Nutr 13, S80.

9. Thomsen AB, Hansen HB, Christiansen C, Green H \& Berger A (2004) Effect of free plant sterols in low-fat milk on serum lipid profile in hypercholesterolemic subjects. Eur J Clin Nutr 58, 860-870.

10. Lichtenstein AH \& Deckelbaum RJ (2001) AHA Science Advisory. Stanol/sterol ester-containing foods and blood cholesterol levels. A statement for healthcare professionals from the Nutrition Committee of the Council on Nutrition, Physical Activity, and Metabolism of the American Heart Association. Circulation 103, 1177-1179.

11. Ostlund RE Jr (2002) Phytosterols in human nutrition. Annu Rev Nutr 22, 533-549.

12. Wasan KM, Najafi S, Peteherych KD \& Pritchard PH (2001) Effects of a novel hydrophilic phytostanol analog on plasma lipid concentrations in gerbils. J Pharm Sci 90, 1795-1799.

13. Wasan KM, Najafi S, Wong J, Kwong M \& Pritchard PH (2001) Assessing plasma lipid levels, body weight, and hepatic and renal toxicity following chronic oral administration of a water soluble phytostanol compound, FM-VP4, to gerbils. J Pharm Pharm Sci 4, 228-234.

14. Lukic T, Wasan KM, Zamfir D, Moghadasian MH \& Pritchard PH (2003) Disodium ascorbyl phytostanyl phosphate reduces plasma cholesterol concentrations and atherosclerotic lesion formation in apolipoprotein E-deficient mice. Metabolism 52, $425-431$.

15. Child P \& Kuksis A (1986) Investigation of the role of micellar phospholipid in the preferential uptake of cholesterol over sitosterol by dispersed rat jejunal villus cells. Biochem Cell Biol 64, $847-853$.

16. Ikeda I, Tanaka K, Sugano M, Vahouny GV \& Gallo LL (1988) Inhibition of cholesterol absorption in rats by plant sterols. $J$ Lipid Res 29, 1573-1582.

17. Vanstone CA, Raeini-Sarjaz M \& Jones PJ (2001) Injected phytosterols/stanols suppress plasma cholesterol levels in hamsters. J Nutr Biochem 12, 565-574.

18. Berge KE, Tian H, Graf GA, Yu L, Grishin NV, Schultz J, Kwiterovich P, Shan B, Barnes R \& Hobbs HH (2000) Accumulation of dietary cholesterol in sitosterolemia caused by mutations in adjacent ABC transporters. Science 290, 1771-1775.

19. Lee MH, Lu K, Hazard S, Yu H, et al. (2001) Identification of a gene, ABCG5, important in the regulation of dietary cholesterol absorption. Nat Genet 27, 79-83.

20. Heimerl S, Langmann T, Moehle C, Mauerer R, Dean M, Beil FU, von Bergmann K \& Schmitz G (2002) Mutations in the human ATP-binding cassette transporters ABCG5 and ABCG8 in sitosterolemia. Hum Mutat 20, 151.

21. Yu L, Hammer RE, Li-Hawkins J, Von Bergmann K, Lutjohann D, Cohen JC \& Hobbs HH (2002) Disruption of Abcg5 and
Abcg8 in mice reveals their crucial role in biliary cholesterol secretion. Proc Natl Acad Sci U S A 99, 16237-16242.

22. Yu L, Li-Hawkins J, Hammer RE, Berge KE, Horton JD, Cohen JC \& Hobbs HH (2002) Overexpression of ABCG5 and ABCG8 promotes biliary cholesterol secretion and reduces fractional absorption of dietary cholesterol. J Clin Invest 110, 671-680.

23. Field FJ, Born E \& Mathur SN (2004) Stanol esters decrease plasma cholesterol independently of intestinal ABC sterol transporters and Niemann-Pick C1-like 1 protein gene expression. $J$ Lipid Res 45, 2252-2259.

24. Calpe-Berdiel L, Escola-Gil JC, Ribas V, Navarro-Sastre A, Garces-Garces J \& Blanco-Vaca F (2005) Changes in intestinal and liver global gene expression in response to a phytosterolenriched diet. Atherosclerosis 181, 75-85.

25. Plosch T, Kruit JK, Bloks VW, Huijkman NC, Havinga R, Duchateau GS, Lin Y \& Kuipers F (2006) Reduction of cholesterol absorption by dietary plant sterols and stanols in mice is independent of the Abcg5/8 transporter. J Nutr 136, 2135-2140.

26. Suckling KE \& Jackson B (1993) Animal models of human lipid metabolism. Prog Lipid Res 32, 1-24.

27. Kris-Etherton PM \& Dietschy J (1997) Design criteria for studies examining individual fatty acid effects on cardiovascular disease risk factors: human and animal studies. Am J Clin Nutr 65, 1590S-1596S.

28. Warnick GR, Benderson J \& Albers JJ (1982) Dextran sulfate$\mathrm{Mg}^{2+}$ precipitation procedure for quantitation of high-densitylipoprotein cholesterol. Clin Chem 28, 1379-1388.

29. Friedewald WT, Levy RI \& Fredrickson DS (1972) Estimation of the concentration of low-density lipoprotein cholesterol in plasma, without use of the preparative ultracentrifuge. Clin Chem 18, 499-502.

30. Ntanios FY \& Jones PJ (1999) Dietary sitostanol reciprocally influences cholesterol absorption and biosynthesis in hamsters and rabbits. Atherosclerosis 143, 341-351.

31. Plosch T, van der Veen JN, Havinga R, Huijkman NC, Bloks VW \& Kuipers F (2006) Abcg5/Abcg8-independent pathways contribute to hepatobiliary cholesterol secretion in mice. Am J Physiol Gastrointest Liver Physiol 291, G414-G423.

32. Repa JJ, Berge KE, Pomajzl C, Richardson JA, Hobbs H \& Mangelsdorf DJ (2002) Regulation of ATP-binding cassette sterol transporters ABCG5 and ABCG8 by the liver X receptors $\alpha$ and $\beta$. J Biol Chem 277, 18793-18800.

33. Repa JJ, Dietschy JM \& Turley SD (2002) Inhibition of cholesterol absorption by SCH 58053 in the mouse is not mediated via changes in the expression of mRNA for ABCA1, ABCG5, or ABCG8 in the enterocyte. J Lipid Res 43, 1864-1874.

34. Dieter MZ, Maher JM, Cheng X \& Klaassen CD (2004) Expression and regulation of the sterol half-transporter genes ABCG5 and ABCG8 in rats. Comp Biochem Physiol C Toxicol Pharmacol 139, 209-218.

35. Duan LP, Wang HH \& Wang DQ (2004) Cholesterol absorption is mainly regulated by the jejunal and ileal ATP-binding cassette sterol efflux transporters Abcg5 and Abcg8 in mice. $J$ Lipid Res 45, 1312-1323.

36. Davis HR Jr, Zhu LJ, Hoos LM, et al. (2004) Niemann-Pick C1 Like 1 (NPC1L1) is the intestinal phytosterol and cholesterol transporter and a key modulator of whole-body cholesterol homeostasis. J Biol Chem 279, 33586-33592.

37. Horton JD, Cuthbert JA \& Spady DK (1995) Regulation of hepatic $7 \alpha$-hydroxylase expression and response to dietary cholesterol in the rat and hamster. J Biol Chem 270, 5381-5387. 